\title{
Elucidating the major mechanisms that control global marine cadmium distributions with AIBECS
}

\footnotetext{
BENOIT PASQUIER $^{1 *}$ AND SETH JOHN $^{1 *}$

${ }^{1}$ Univ. of Southern California, Dep. of Earth Sciences, LA, CA 90089, USA (*correspondence: bp 358@usc.edu)

Marine dissolved cadmium (Cd) concentrations are tightly correlated with those of major macronutrient phosphate $\left(\mathrm{PO}_{4}\right)$ with an average $\mathrm{Cd}: \mathrm{PO}_{4}$ of $\sim(0.23 \pm 0.11)$ $\mathrm{nmolCd} / \mu \mathrm{molP}$ throughout the global oceans. Yet, observations show systematic deviations from the mean $\mathrm{Cd}: \mathrm{PO}_{4}$ across ocean regions, with generally higher $\mathrm{Cd}: \mathrm{PO}_{4}$ in the deep ocean. Preferential $\mathrm{Cd}$ uptake, preferential $\mathrm{Cd}$ remineralization/respiration, and cadmium sulfide (CdS) precipitation, are among the mechanisms that have been suggested to qualitatively explain these systematic deviations. However, the literature is lacking in quantitative modelling studies that could provide determining insights in the global marine $\mathrm{Cd}$ cycle.

Here we present a family of inverse models of the marine Cd cycle. Different hypothetical biogeochemical processes, which are encoded as local sources and sinks, are embedded in the state-of-the-art data-assimilated ocean circulation of the Ocean Circulation Inverse Model (OCIM). The biogeochemical parameters of each $\mathrm{Cd}$-cycling model are optimized to minimize the mismatch with GEOTRACES data. These inverse models are then used to evaluate the likelihood of biogeochemical mechanisms and select those that best explain the distribution of marine $\mathrm{Cd}$. Preliminary results suggest that sulfide precipitation, which may affect the long-term marine $\mathrm{Cd}$ inventory, has little effect on the largescale spatial $\mathrm{Cd}$ gradients. Preferential $\mathrm{Cd}$ uptake and remineralization are consistent with $\mathrm{Cd}$ concentration patterns. However, simulations based on these mechanisms alone do not reproduce isotope observations $\left(\delta^{114} \mathrm{Cd}\right)$, which may be instead explained by additional cycling by heterotrophs in the mesopelagic.

The models are generated using the AIBECS framework, a new Julia package for marine biogeochemists and paleoceanographers to easily and efficiently simulate global marine tracers in steady state.
} 